\title{
DEVELOPMENT OF OZONE WATER DISINFECTION
}

\author{
Pralay Majumdar \\ Arabinda Pally, P.O.:- Suri, Dist.:- Birbhum, PIN: 731101,pralay_speaking@rediffmail.com
}

\begin{abstract}
The aim is to develop a portable ozone generator which can produce the ozone gas in the discharge tube by corona discharge method. By this method oxygen is converted to ozone by the application of high voltage through the line output transformer. Some electronics components are being used to generate the modulated output of high and low frequency to avoid the high voltage shock.

Titration experiment has been carried out to detect the ozone gas as well as the amount of ozone output from the discharge tube.

Ozone has numerous beneficial effects for mankind. Out of them the impure or surface water where the coli form group of bacteria may be present has to be disinfected by the application of ozone through the multiple tube fermentation technique or the presumptive phase.
\end{abstract}

Key words: Ozone generator, Calibration test, Presumptive phase

\section{INTRODUCTION:}

The block diagram representation of the overall project concern and concept of ozone generation is being shown in figure1 and figure 2 respectively.

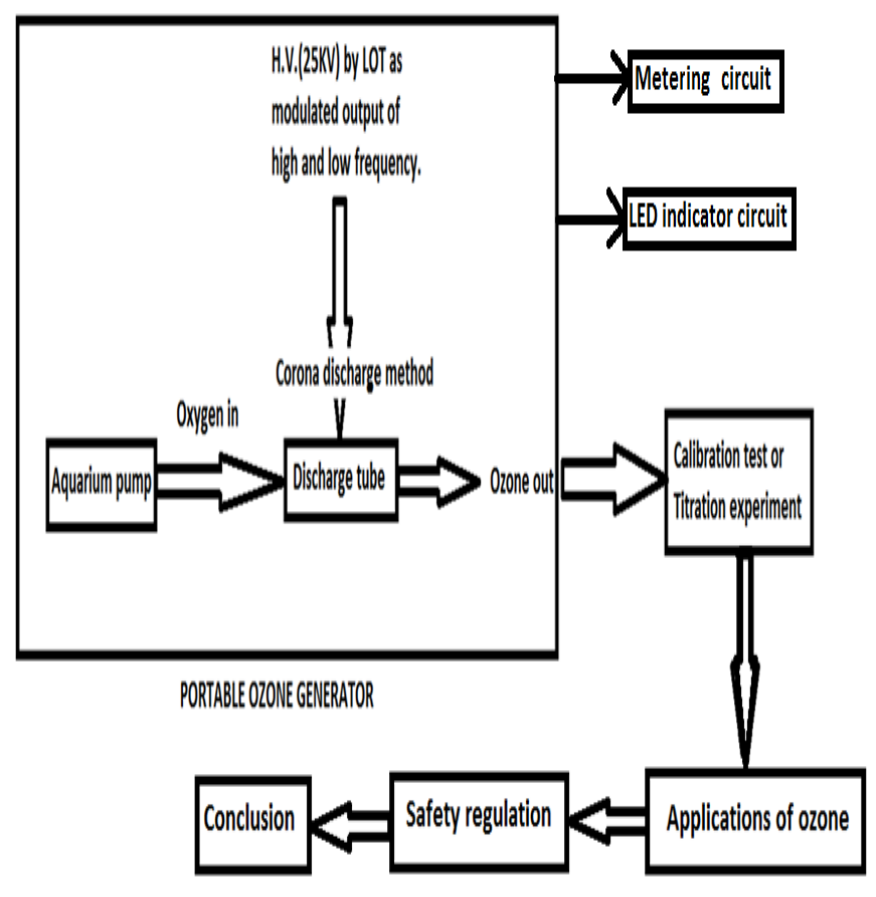

Figure1

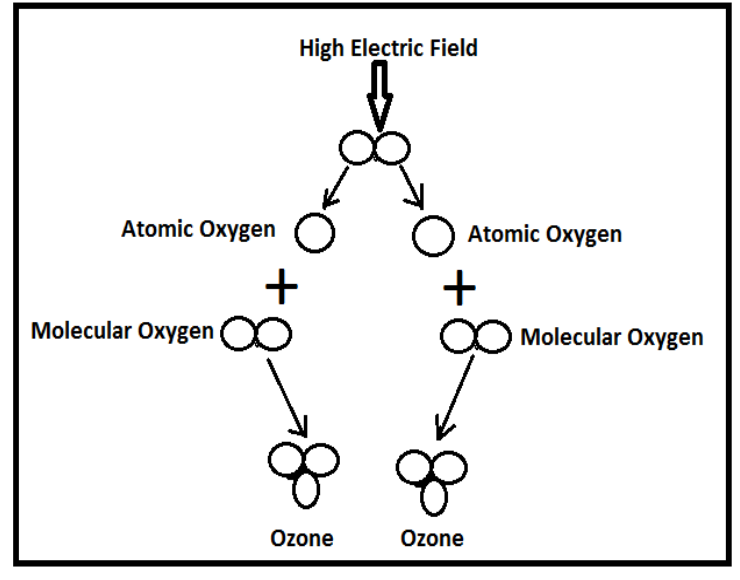

Figure2

The air is supplied to the discharge tube by air pump. The air flows through the cylindrical space of discharge tube. The unit employs high voltage of above $18 \mathrm{kv}$ at a frequency of $15 \mathrm{KHz}$ $-20 \mathrm{KHz}$ which would not cause lethal shock. Shock voltages are not dangerous at these high frequencies. While at $50 \mathrm{~Hz}$ these high voltages are quite dangerous. Discharging in the gas gap takes place only when the applied voltage is increasing.

\section{DESIGN OF THE OZONE GENERATOR:}

Ozone generator circuit can be designed by the following components:

$>$ Pulse generator,

$>$ Low voltage supply (12v),

$>$ AC input (160v), 
$>$ Switched mode power supply which converts $230 \mathrm{v}$ ac to $160 \mathrm{v}$ ac and $15 \mathrm{v} \mathrm{dc}$,

$>$ Ferrite core transformer (LOT),

$>$ The metering circuit and

$>$ LED indicator circuit.

The output of the switched mode power supply i.e. $15 \mathrm{v}$ dc can be converted to $12 \mathrm{v}$ dc by versatile regulated power supply which is shown in figure below.

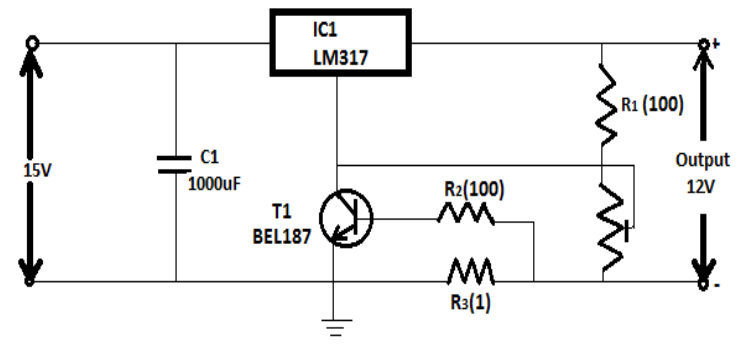

Versatile Regulated Power Supply

Figure3

The circuit as shown in figure generates the controlled high frequency of above $18 \mathrm{kv}$. A simple pulse generator is realized by using two CMOS integrated circuits. CD4069 is a hex inverter while CD4011 is a quad NAND gate. Two of the 4069 gates are used to generate $15-20 \mathrm{KHz}$ pulses. The second oscillator also uses the gates from the same IC CD4069 and works at around $2 \mathrm{KHz}$. Therefore, when the outputs of the two oscillators are combined using the NAND gate, one gets the modulated output of high and low frequency. Such an excitation of the discharge tube has been found to be very efficient and less heat producing as compared to plain high or a plain low frequency excitation.

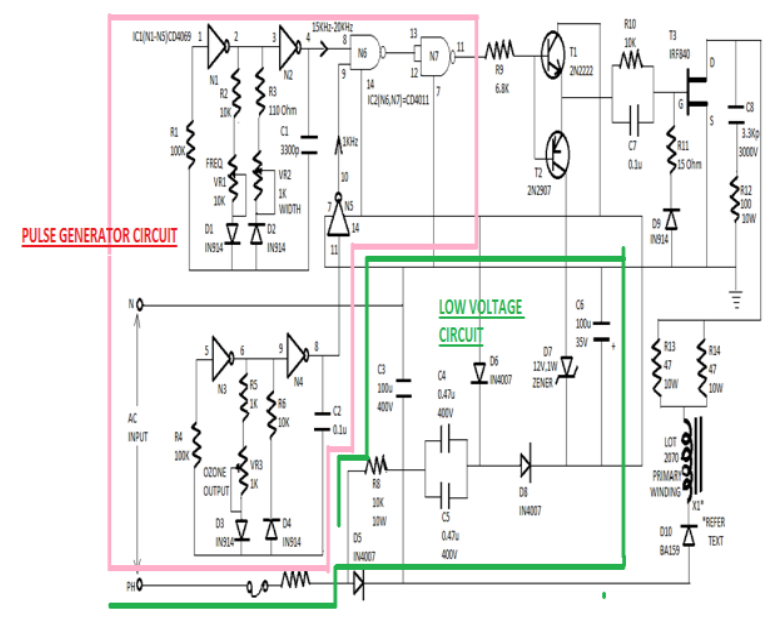

Figure4: Schematic diagram of portable ozone generator.

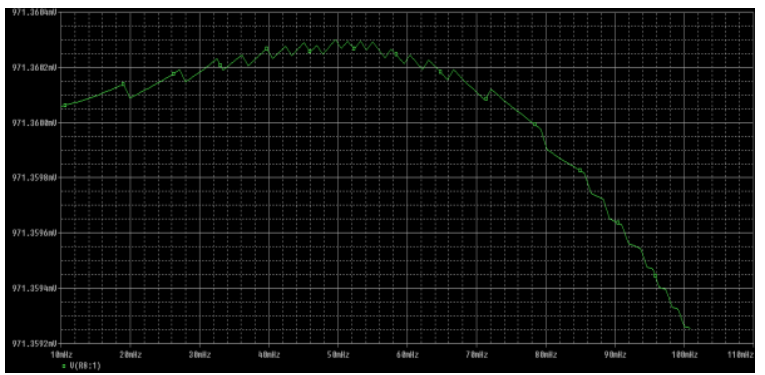

Figure5: Modulated output of high and low frequency.

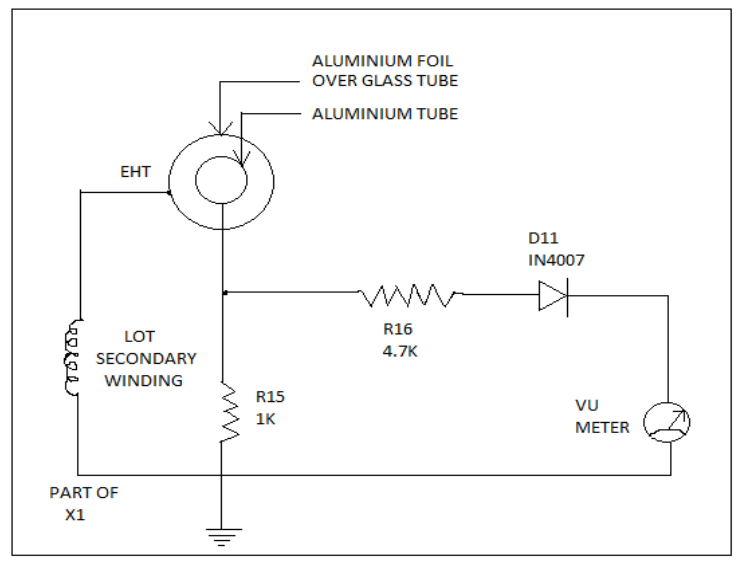

Figure6: The metering circuit.

The reading of the meter indicates that there is a discharge.

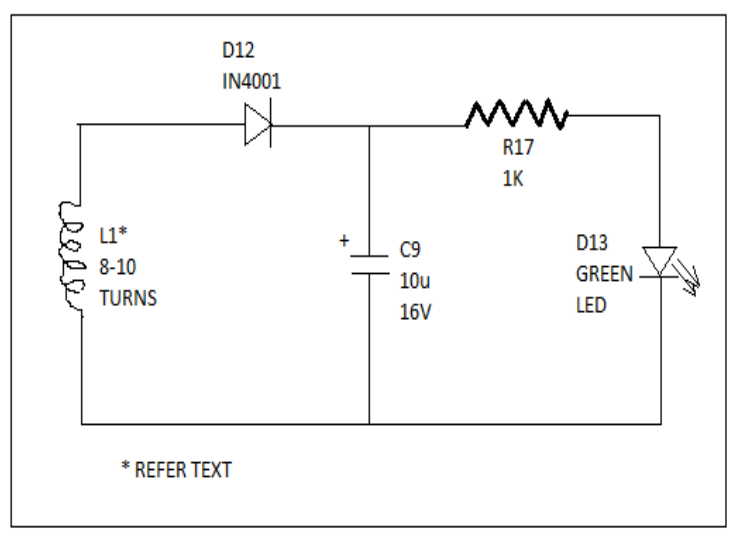

Figure7: LED indicator circuit.

The glowing of the LED indicates that the circuit along with Line Output Transformer (LOT) is working.

After the whole assembly is checked and main supply is given, one can watch the meter reading and green LED on the panel. The sound of the air pump can be heard of course but one can hear the corona sound distinctly. A smell like that of rotten fish from the tube indicates presence of ozone. 


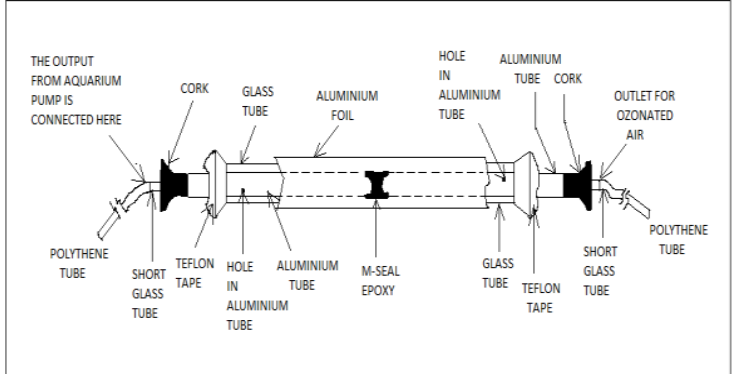

Figure8: Construction of the discharge tube.

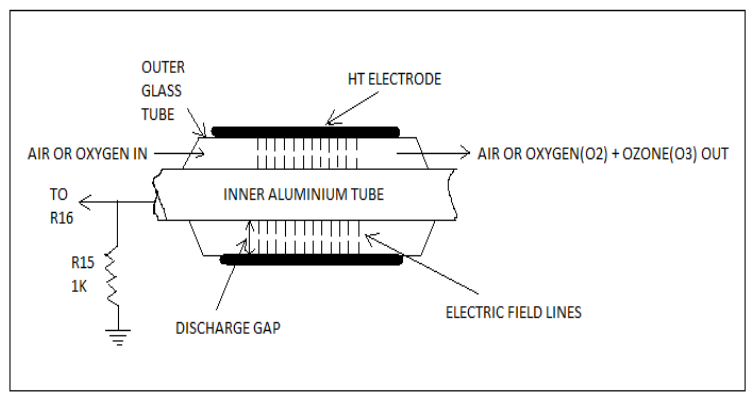

Figure9: Airflow through cylindrical space of discharge tube.

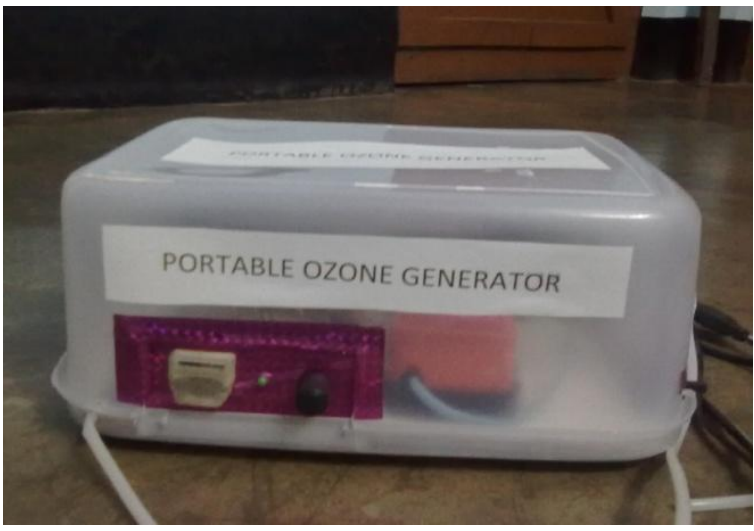

Figure10: Development of an ozone generator

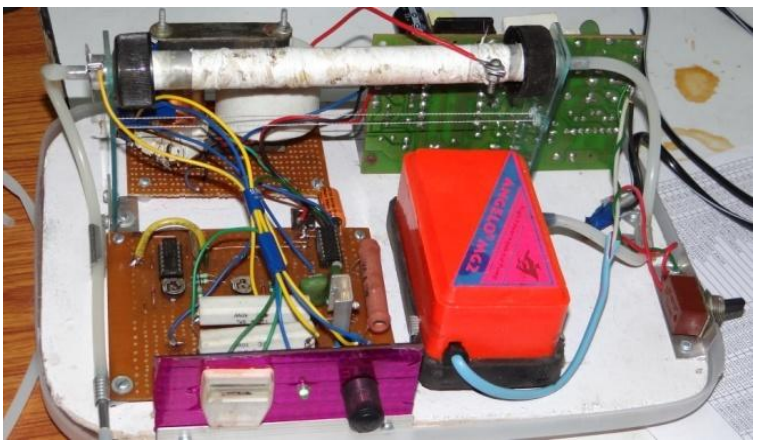

Figure11

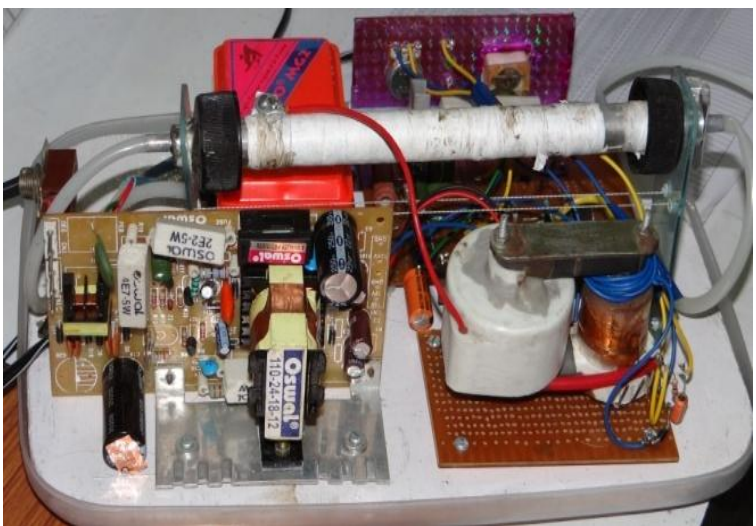

Figure12: Constructional view of an ozone generator.

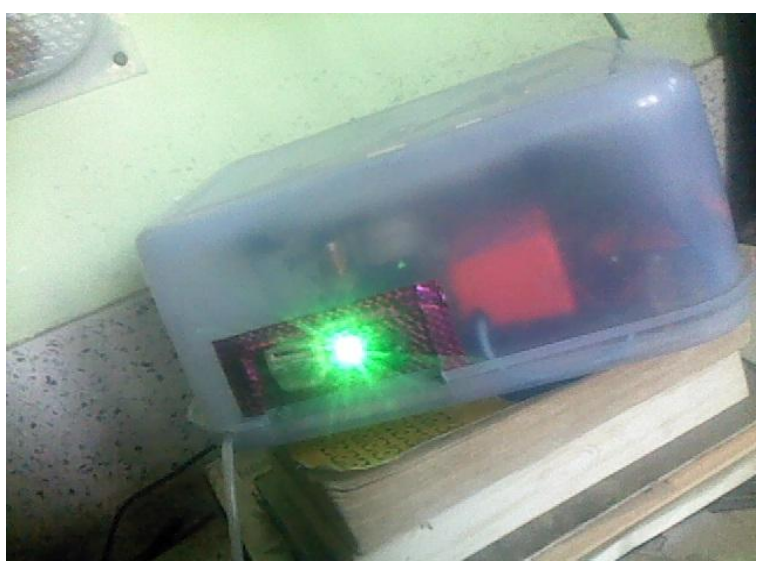

Figure13: Ozone generator connected to the main supply.

Detection of ozone: Detection of ozone from the discharge tube can be done by calibration or titration experiment.

Potassium iodide (KI) solution can be converted into the iodine gas by ozone. Take a known quantity of KI solution and bubble the ozonated air from ozone generator through it for a define time (1 to3 minutes). Addition of small amount of sulphuric acid $\left(\mathrm{H}_{2} \mathrm{SO}_{4}\right)$ to the above solution makes the yellow colour iodine concentration more clear. The free liberated iodine can be estimated by titration experiment with starch and sodium thiosulphate. Thus, by knowing how much iodine gas has been liberated, it can be found how much ozone has been absorbed in the solution by quantitative analysis. This gives the gas output from the tube in $\mathrm{mg} / \mathrm{min}$.

Reaction involved:

$$
\begin{gathered}
2 \mathrm{KI}+\mathrm{O}_{3}+\mathrm{H}_{2} \mathrm{O}=2 \mathrm{KOH}+\mathrm{O}_{2}+\mathrm{I} \\
\mathrm{I}_{2}+\mathrm{STARCH}=\text { Blue or purple colour. }
\end{gathered}
$$

When the above solution is being titrated by sodium thiosulphate $\left(\mathrm{Na}_{2} \mathrm{~S}_{2} \mathrm{O}_{3}\right)$ then its colour will be changed from deep blue to colourless. 


\section{EXPERIMENTAL RESULT:}

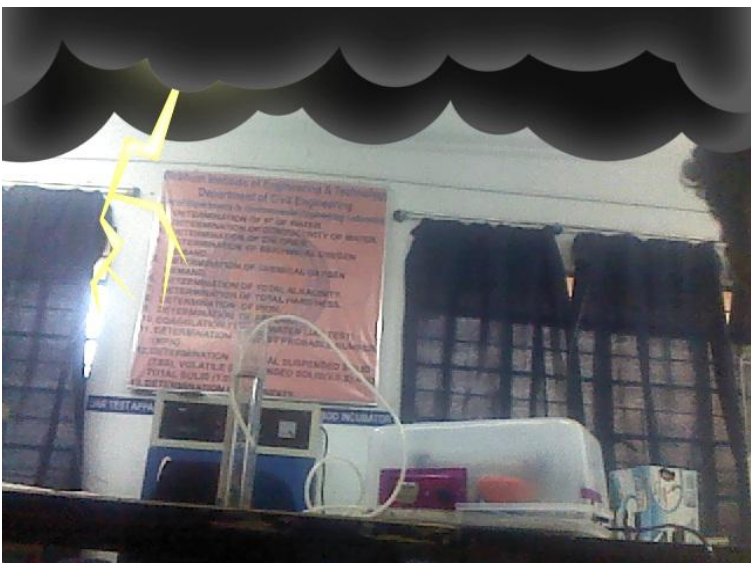

Figure14: Ozone gas is being passed to the KI solution for 2 minutes.

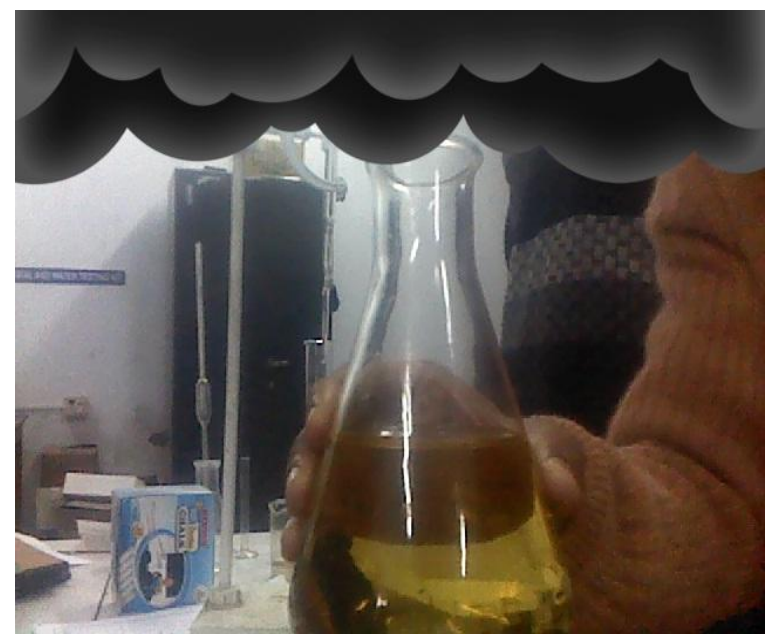

Figure15: Addition of sulphuric acid.

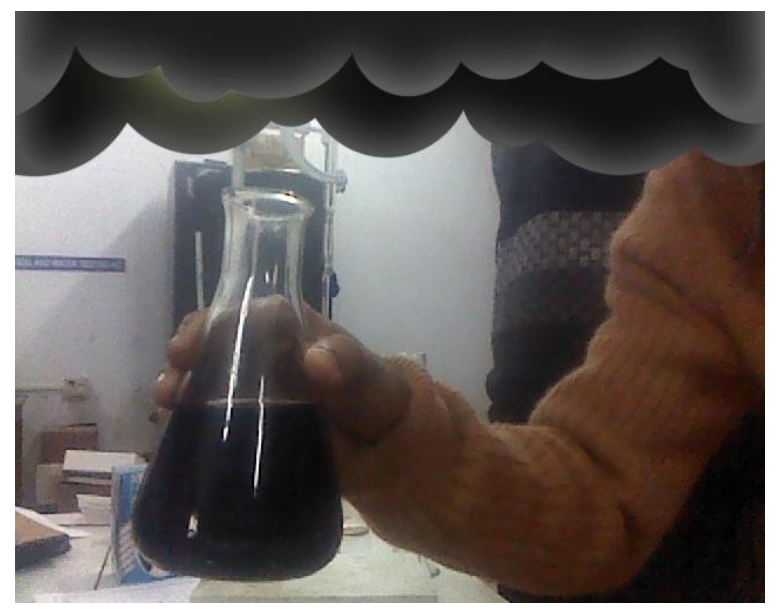

Figure16: Addition of starch.

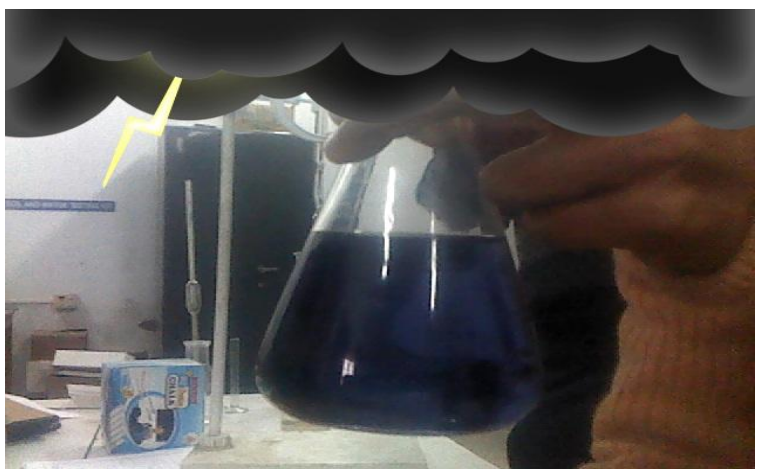

Figure17: Addition of sodium thiosulphate.

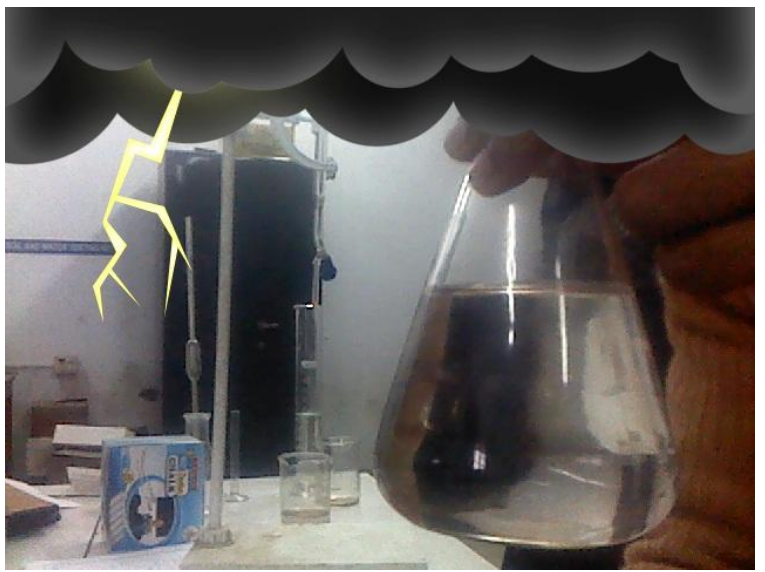

Figure18: Colour is being changed from deep blue to colourless.

Amount of ozone output $=$ Consumed sodium thiosulphate for titration in $\mathrm{mL}$ (from burette reading) $\times$ Atomic weight of ozone $\times$ Normality of sodium thiosulphate/ Ozonation time (in minutes).

$8.6 \times 24 \times 0.005 / 2=0.516 \mathrm{mg} /$ minute.

\section{Application of ozone:}

$>$ Water disinfection;

$>$ Deodorization, freshening of air and air quality management;

$>$ Kill bacteria on food and destroy ethylene, hence enhance the storage life of the food products and looking fresh.

$>$ Sterilization in medical area,

$>$ Aquaculture (fish farming) and aquarium system,

$>$ Sanitize swimming pools,

$>$ Cigarette and cigar smoke removal.

$>$ Mosquito repulsion,

$>$ Take off the smell of the kitchen or the toilet,

$>$ Mouth washing,

$>$ Ozone therapy: Skin irregularities and skin related diseases, ozone bath, ozone infusion etc. 
$>$ Hydroponics and many other applications.

Ozone as water disinfection: Ozone is added to water to kill diseases mainly bacteria. It also helps to eliminate chlorine, pesticides and other toxic chemicals found in water. Ozone does not replace a water filter and soften water or remove rust. It kills pathogens 3000 times faster than chlorine. It is also safer since chlorine is highly carcinogenic and can react with blood cholesterol causing it to coagulate on the walls of arteries forming plaque. Ozone kills $99.9 \%$ all coli form group bacteria like E. coli, S. Areus, Bacillus subtillis etc.

Determination of Member of coli form group: The coli form group comprises all aerobic and facultative gram negative, nonspore forming, rod shaped bacteria that ferment lactose with gas and acid formation within 48 hours at $35^{\circ} \mathrm{c}$.

The standard test for coli form group may be carried out by the multiple tube fermentation technique (through the presumptive phase).

Presumptive phase:

Apparatus: Laminar air flow bench, Autoclave, Incubator.

Glassware: Test tubes, Pipettes, Beaker, Durham tubes, Sample bottle, Aluminium foil etc.

Reagents and culture medium:

Lauryl tryptose broth:

Tryptose .................. $20.0 \mathrm{~g}$

Lactose ...................... $5.0 \mathrm{~g}$

Dipotassium hydrogen phosphate.... $2.75 \mathrm{~g}$

Potassium dihydrogen phosphate ....2.75 g

Sodium chloride ........................... $5.0 \mathrm{~g}$

Sodium lauryl sulphate .................... $0.1 \mathrm{~g}$

Reagent - grade water .................. $1 \mathrm{~L}$

Add dehydrated ingredients to $300 \mathrm{~mL}$ water and mix thoroughly.

Procedure: Shake the water sample thoroughly before making dilution and inoculation.

- Select dilution according to the expected coli form.

- After preparing the medium, $9 \mathrm{~mL}$ of medium is taken in each culture tube (total 15 culture tube is taken).

- Durham's tube filled with medium $(1 \mathrm{~mL})$ put in inverted position in each culture tube so it is completely free of bubble.

- The tubes are cotton plugged and were sterilized by autoclaving (15lb pressure for 15 minutes).

- Medium is cooled at room temperature and $10 \mathrm{~mL}, 1 \mathrm{Ml}$ and $0.1 \mathrm{~mL}$ water sample poured in different tube by sterilized pipettes in laminar air flow bench.

- All the tubes are properly labelled and incubate at $35^{\circ} \mathrm{c}$ for 48 hours.

- Changes of colour and production of gas i.e. bubble formation in Durham's vial was observed after 24 hours which indicates the production of gas and acid respectively.

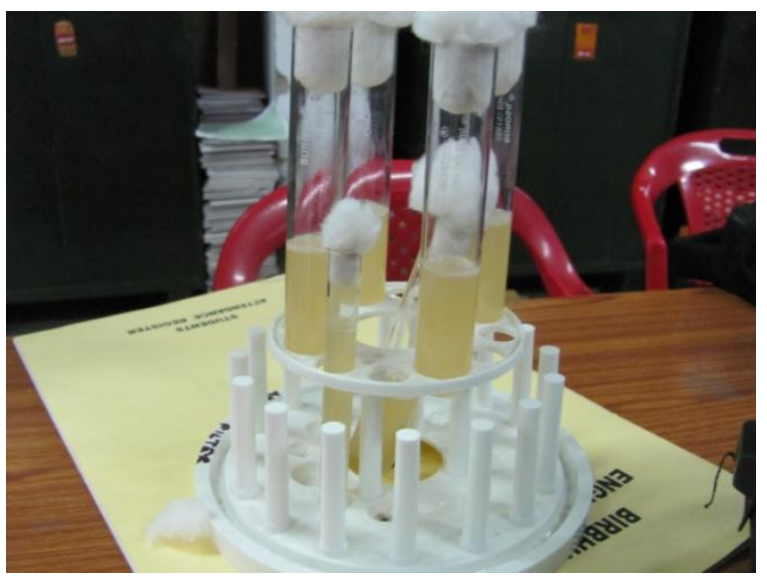

Figure19: Acid and gas is being produced, change of colour also being noticed (i.e. coli form group present) when ozone is not passed to the sample (positive test).

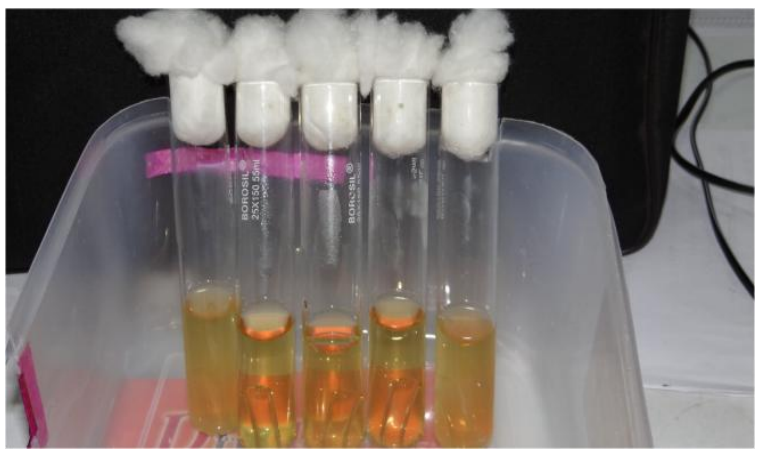

Figure20: No acid and gas i.e. bubble formation in the Durham's tube when the ozone is being passed to the sample (Negative test).

Source of sample is pond.

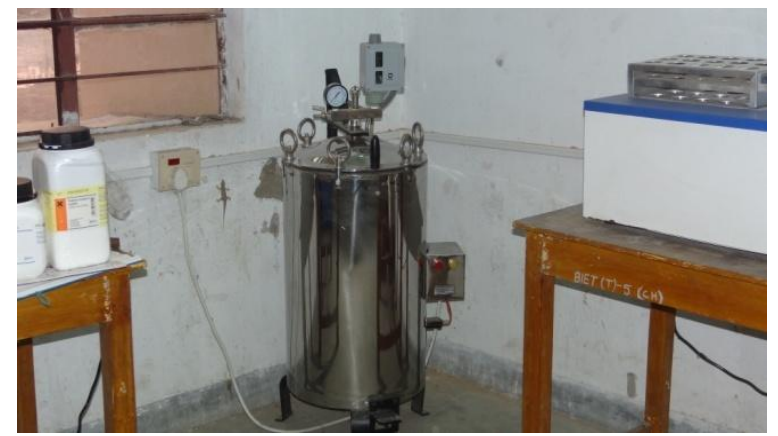

Figure21: Autoclave. 


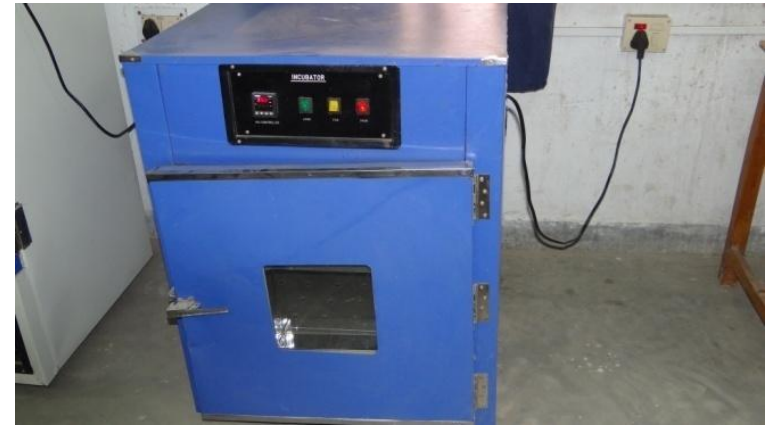

Figure22: Incubator.

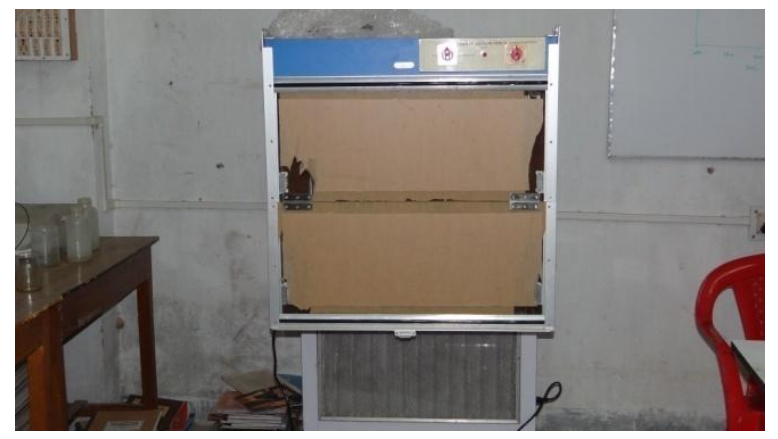

Figure23: Laminar air flow bench.

\section{ADVANTAGES AND DISADVANTAGES OF}

\section{OZONE:}

- Ozone has a tendency to revert back to its original form in about 10 to 20 minutes, in the atmosphere. Therefore, it is necessary in any ozone application to generate ozone as and when required for use since it cannot be kept stored and reduces the bad effects caused by ozone.

- Health effects for high level ozone exposure are a genuine concern and be looked at before using the technology. Studies have shown that when ozone levels are high, possible side effects including coughing, irritation of the throat and uncomfortable sensations in the chest may be occurred. Asthmatics are more severely affected by the reduced lung function.

\section{FUTURE SCOPE}

Recently cancer cell growth has been retards unprecedently by the application of the right amount of ozone and the research is continuing by the U.S. scientists.

\section{REFERENCES}

[1] "Portable ozone generator" by K. Padmanabhan, S. Ananthi and Kirit Patel, Electronics for you, June 2000.

[2] "Versatile regulated power supply" by Amrit Viv Tiwana, Practical Electronic Circuits, March 1997.
[3] "ENVIRONMENTAL PROTECTION ENERGY". 1989. National primary drinking water regulations: analytical techniques; coli-form bacteria, final rule. Federal register 54(135):29998 (July17, 1989).

[4] "Standard method for examination of ozone dose", American Public Health Association (APHA), 1998. 